\title{
Laser-induced graphene (LIG)-driven medical sensors for health monitoring and diseases diagnosis
}

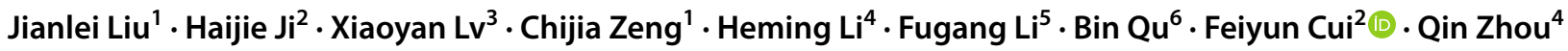

Received: 28 September 2021 / Accepted: 26 December 2021 / Published online: 10 January 2022

(c) The Author(s), under exclusive licence to Springer-Verlag GmbH Austria, part of Springer Nature 2022

\begin{abstract}
Laser-induced graphene (LIG) is a class of three-dimensional (3D) porous carbon nanomaterial. It can be prepared by direct laser writing on some polymer materials in the air. Because of its features of simplicity, fast production, and excellent physicochemical properties, it was widely used in medical sensing devices. This minireview gives an overview of the characteristics of LIG and LIG-driven sensors. Various methods for preparing graphene were compared and discussed. The applications of the LIG in biochemical sensors for ions, small molecules, microRNA, protein, and cell detection were highlighted. LIG-based physical physiological sensors and wearable electronics for medical applications were also included. Finally, our insights into current challenges and prospects for LIG-based medical sensing devices were presented.
\end{abstract}

Keywords Laser-induced graphene (LIG) · Medical sensors · Electric/electrochemical sensors · Wearable electronics · Diseases diagnosis $\cdot$ POCT

Jianlei Liu and Haijie Ji contributed equally

Feiyun Cui

fcui100@foxmail.com

Qin Zhou

zhouqin@hrbmu.edu.cn

1 Department of Laboratory Medicine and Pathology, Foshan Fosun Chancheng Hospital, Foshan 528000, Guangdong, China

2 The Ministry of Education Key Laboratory of Clinical Diagnostics, School of Laboratory Medicine, Chongqing Medical University, Chongqing 400016, China

3 Department of Dermatology, West China Hospital, West China School of Medicine, Sichuan University, Chengdu 610041, China

4 College of Basic Medical Sciences, Harbin Medical University, Harbin 150081, China

5 Shanghai Engineering Research Center of iPOCT Medicine, Shanghai Industry Technology Innovation Strategic Alliance of iPOCT Medicine, Shanghai Upper Bio Tech Pharma Co., Ltd., Shanghai 201201, China

6 Biophysics, Center for Integrative Physiology and Molecular Medicine (CIPMM), School of Medicine, Saarland University, 66421 Homburg, Germany

\section{Introduction}

Sensors are a type of promising diagnostic tools for laboratory medicine [1]. Sensors-driven point-of-care testing (POCT) plays a unique role in the personalized health monitoring, diseases diagnosis, and global public health events warning [2]. It enables home testing, community testing, and large-scale preliminary screening without the support of large medical instruments. It is worth mentioning that the COVID-19 epidemic has attracted more attention to medical sensors which have potentials to timely track symptomatic infection or asymptomatic infection and remotely monitor isolated patients [3]. Hence, developing ultrasensitive and low-cost medical sensors is extremely important.

The development of medical sensors strongly depends on the advances of nanomaterials $[4,5]$. Graphene has excellent physical and chemical properties, such as high carrier mobility rate, high thermal conductivity, excellent mechanical properties, and larger specific surface area [6-9]. These performances enable it widely applied in sensors, optics, biology, medicine, energy storage, and other fields. Graphene has been extensively applied in medical sensors such as field-effect transistors (FETs) biosensor [10], artificial throat [11], artificial skin [12], wearable human-machine interface [12, 13], and artificial muscle [14]. Laser-induced graphene (LIG), which was introduced in 2014 by Lin and 
coworkers, has attracted widespread attention in recent years $[15,16]$. It is a type of three-dimensional (3D) porous carbon nanomaterial fabricated by direct laser writing with carbon dioxide $\left(\mathrm{CO}_{2}\right)$ lasers on polymer materials in the air. It was also named laser-ablated graphene (LAG), laser-scribed graphene (LSG), or laser-derived graphene (LDG) [17]. The morphology of the LIG can be easily controlled by a computer, which is of great significance to the development of highly sensitive electric/electrochemical sensors and wearable electronics for medical biomarkers detection. Polyimide (PI) and its complexes are commonly employed for preparing the LIG. Polyetherimide (PEI), potato skin wood, cork, coconut, cloth, and polysulfone (PSU) are also reported as the base polymer materials for engraving $3 \mathrm{D}$ porous graphene [18-20]. In the process of LIG preparation, infrared $\mathrm{CO}_{2}$ laser (commonly, the wavelength of the excitation light is $10.6 \mu \mathrm{m})$ [21] is commonly used. The main principle is that during the laser scanning of the base polymer material, the nitrogen-carbon bonds, carbon-oxygen bonds, and carbon-oxygen bonds of the base material are broken, and then rearranged to form a $3 \mathrm{D}$ porous graphene structure [22]. In addition to the infrared $\mathrm{CO}_{2}$ laser, ultraviolet (UV) laser [23] and visible laser [24] have been confirmed to prepare the LIG.

With worldwide research efforts, LIG-driven sensors have been successfully applied in different fields, including clinical diagnostics, food safety, and environmental monitoring [25]. It was also applied in energy storage micro-supercapacitors (MSCs) [24, 26], cell culture [27], and fuel cell [28]. Meanwhile, LIG possesses characteristics such as flexibility, chemical resistance, and porosity, which makes useful as a porous channel or electrode material in microfluidic devices [29]. The various applications of LIG are shown in Fig. 1. It is foreseeable that this advanced material will soon bring a new generation of medical sensing device, which will have exciting characteristics and applications [30].

Several LIG-related review articles have been published. Ye and coworkers told a comprehensive story about LIG from its discovery to wide range of applications, including sensors, electrocatalysts, and microfluidics [31]. You and coworkers summarized and discussed the LIG-based flexible electronics [32]. However, this review is mainly focusing on the LIG-driven medical sensors for health monitoring and diseases diagnosis. Applications of the LIG-driven sensors for POCT and in vitro diagnosis (IVD) are emphasized.

\section{Various preparation methods and characteristics of graphene}

The existing methods for preparing graphene include mechanical stripping [33], thermal decomposition [34], epitaxial growth [35], chemical vapor precipitation (CVD)

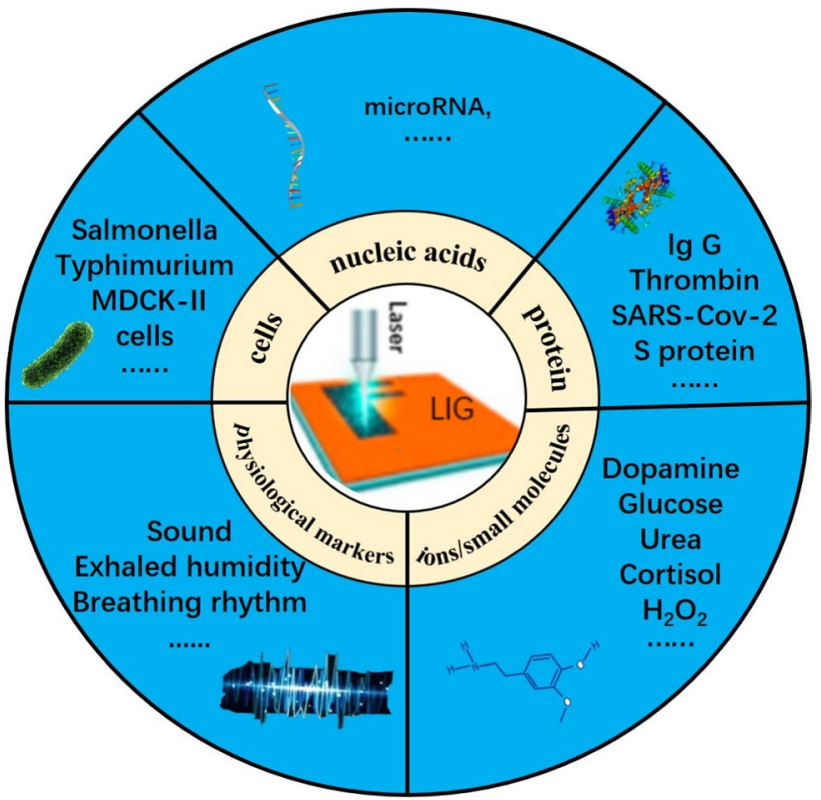

Fig. 1 Applications of LIG in various biosensors and physical physiological sensors

[36, 37], and wet chemical methods [38]. Heat-intensive processing techniques such as silicon carbide thermal decomposition and CVD can be used to grow graphene with almost no defects and high crystal quality [39]. However, the high-temperature conditions limit the types of substrates that can be used for directly growing graphene. Hence, additional processes are usually required to transfer graphene on substrates that are not resistant to high temperatures (such as plastics). The wet chemical method is time-consuming and it requires series of oxidation and reduction steps, extensive washings, and centrifugations. The prepared graphene is less control over the number of sheets and amount of oxygen functionalities. What's more, aqueous solutions of graphene tend to restack to yield the graphite. These existing methods are often plagued by cumbersome manufacturing processes, high energy consumption, and/or low productivity. In addition, the inability to achieve large-area graphene on divers substrates associated with these traditional methods inevitably limits graphene's widespread adoption.

In 2014, Lin and coworkers successfully prepared 3D porous graphene (also known as LIG) by direct writing of a commonly accessible $\mathrm{CO}_{2}$ infrared laser system on the commercial PI [15]. The 3D porous graphene has a high specific surface area $\left(\approx 340 \mathrm{~m}^{2} \cdot \mathrm{g}^{-1}\right)$, high thermal stability $\left(>900{ }^{\circ} \mathrm{C}\right)$, and excellent electrical conductivity $(5 \sim 25$ $\left.\mathrm{S} \cdot \mathrm{cm}^{-1}\right)$. The whole process can be carried out in the air, without any solvent, expensive machine, and costly materials. The method of engraving PI by laser avoids complicated wet chemical methods, and can directly prepare patterned 
structures, laying a good foundation for the wider application of graphene.

For the laser writing or engraving, various process parameters, such as laser wavelength, power, frequency, time, pulse width, and scanning speed, are all of great significance. A satisfactory LIG-based device is often the result of the synergy of multiple laser parameters. As shown in Figs. 2 and 3, by adjusting the laser parameters, different processing effects can be obtained [40].

Doping heteroatom in the LIG is an effective way to improve its sensing properties. Nitrogen [41] and boron [42] have been utilized as doping heteroatoms to tailor the electrochemical performance of the LIG and to enhance its surface wettability and electrical conductivity. Chen's group proposed a method for preparing phosphorus-doped (P-doped) LIG electrodes on the $\mathrm{H}_{3} \mathrm{PO}_{4}$-doped polyimide (PI)/polyvinyl alcohol (PVA) composite flexible film [43]. Figure 4A presents the schematic diagram of the production process of the P-doped LIG interdigitated array electrodes. It was demonstrated that P-doped LIG has enhanced affinity to electrolyte ions on the electrode surface. As a result, the electrode possesses an improved electrochemical performance. The study provides a convenient and potentially efficient method for preparing free-standing heteroatomdoped porous graphene electrodes, which would have broad application in various flexible/wearable electronic devices. A facile methods for the in situ preparation of metal sulfide (MS)-graphene (G) nanocomposite, PbS-G and CdS-G, on indium-tin oxide (ITO) glass was demonstrated by scalable direct laser writing in ambient atmosphere [44]. Through the $\mathrm{CO}_{2}$ laser irradiation of a metal-complex containing polyethersulfone layer on ITO glass, both the formation of LIG and crystallization of laser-induced MS (LIMS) were achieved within one step (Fig. 4B). The fabricated LI-MSG@ITO possesses the porous architecture of the polyethersulfone-derived LIG, in which the LIMS nanocrystals
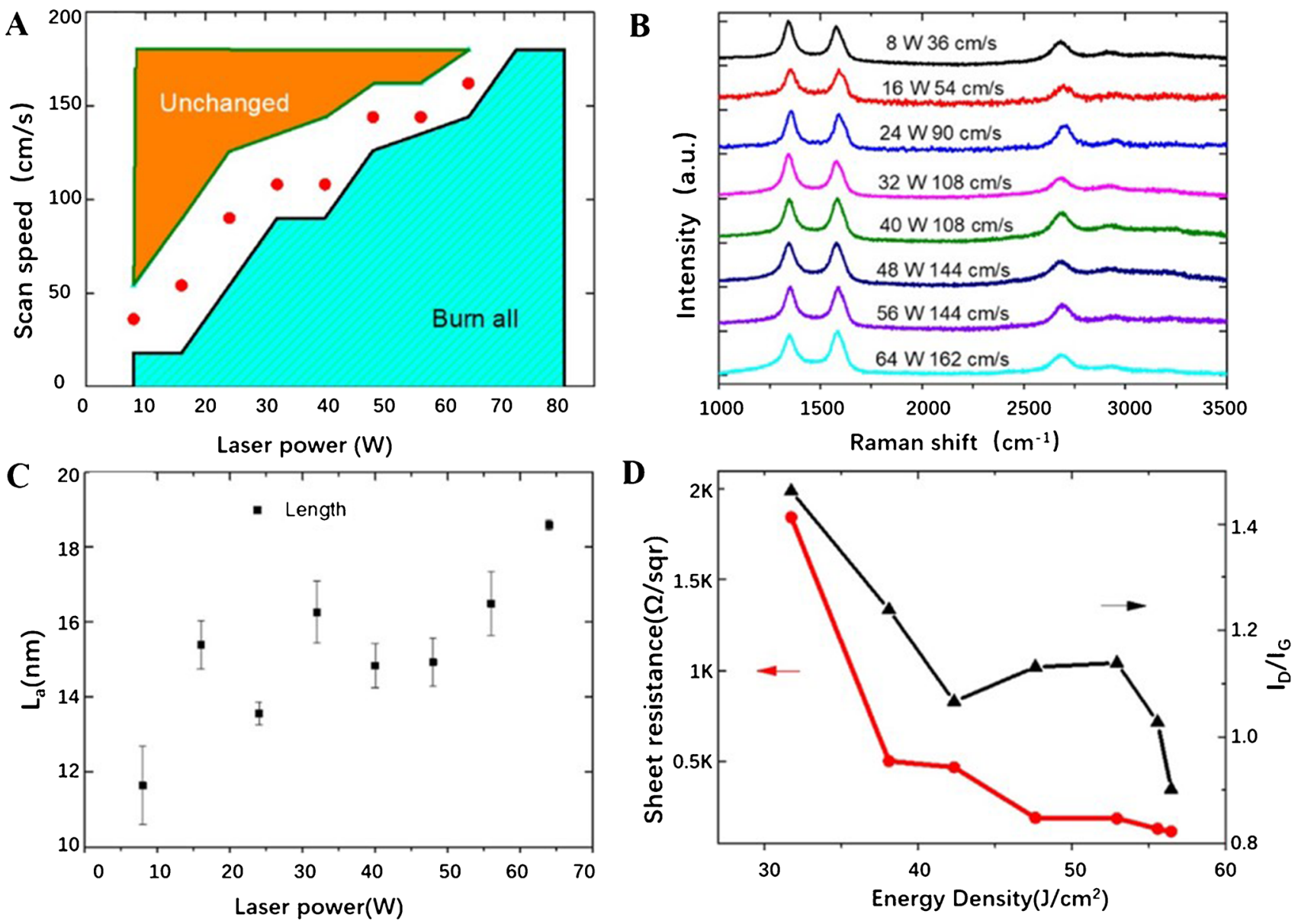

Fig. 2 A The relationship between laser power and laser scanning speed to achieve LIG. In the orange area, no obvious carbonization occurs in the PI film, while in the light green region, the whole PI material was burned away. When the laser parameters are in the white space, LIG with different morphology and properties could be

achieved. B Raman spectra of LIG under different laser conditions. C The correlation between the length of the laser power and the LIG crystal width. D The surface resistance of LIG and the ratio of $\mathrm{I}_{\mathrm{D}} / \mathrm{I}_{\mathrm{G}}$ dependence on laser energy density. Reprinted with permission from ref. [40], Copyright 2020 Elsevier Ltd. 

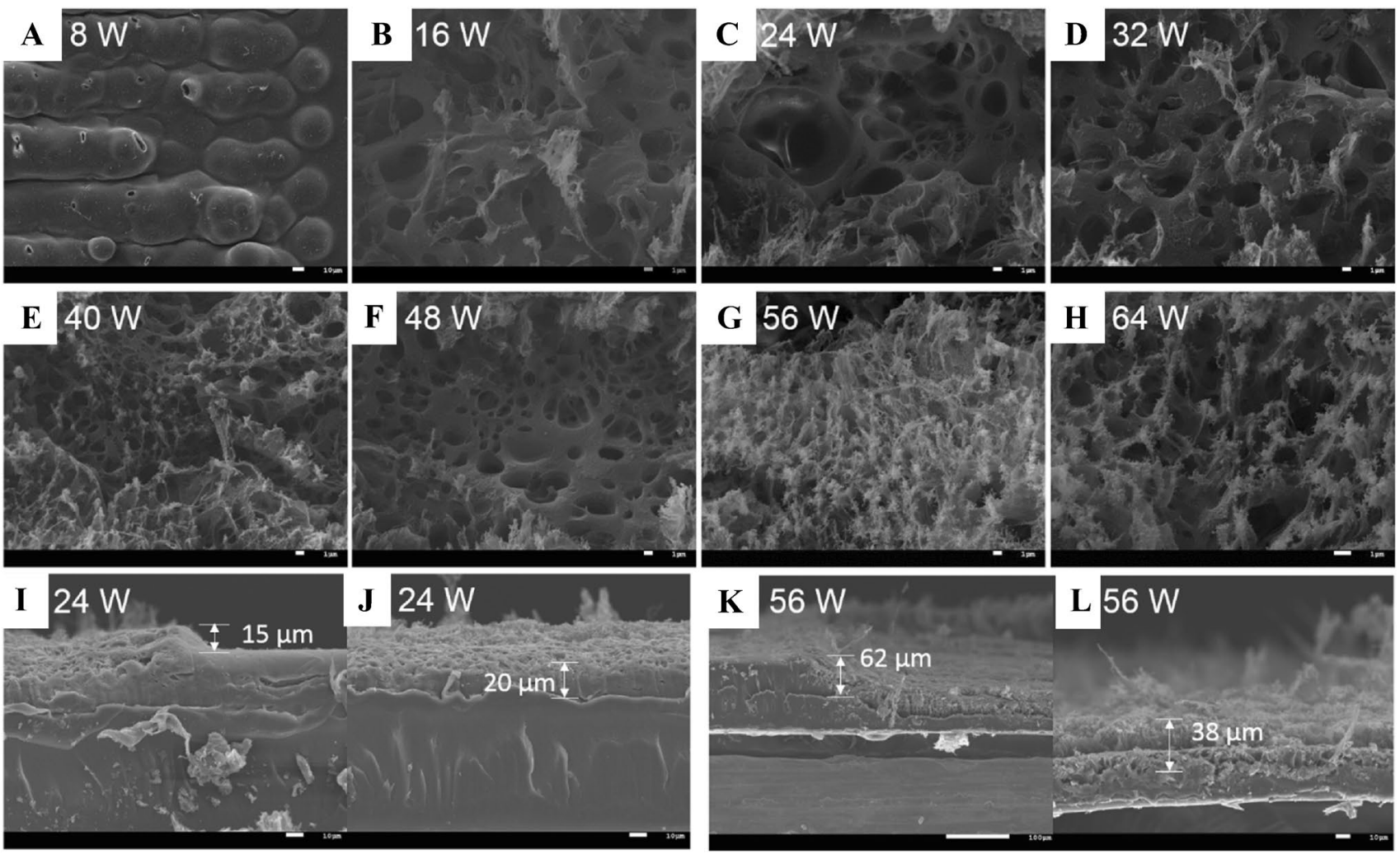

Fig. 3 A-H Scanning electron microscope (SEM) images of the LIG on PI film prepared with various laser parameters with scale bar $1 \mu \mathrm{m}$. I-L The cross-section SEM images of the LIG at different laser

parameters, with scale bar $100 \mu \mathrm{m}(\mathbf{K})$ and $10 \mu \mathrm{m}(\mathbf{L})$. Reprinted with permission from ref. [40], Copyright 2020 Elsevier Ltd.

uniformly decorate the 3D porous graphene sheets with excellent dispersion, showing a stable and fast photocurrent response and good reproducibility.

Through the modification or functionalization of the LIG, the detection of analytes can be achieved sensitively and selectively. The adsorption of analytes on the LIG electrode surface will change the electrode impedance, surface area, and other parameters, and the electrical signals will respond to the variety of parameters $[45,46]$.

\section{LIG-based sensors}

The LIG has been more and more prevalent for developing sensors. It shows great potential in biochemical sensors and physical physiological sensors. These sensors have great potential in monitoring the normal life activities of the human body. Some of them can be used as wearable devices to monitor human biomarkers continuously. In this section, the wearable devices were listed independently.

An biochemical sensor is an analytical device that can convert biological or chemical reactions into measurable physical signals, and can provide quantitative assessment of analyte concentration [47]. The basic principle of the

biochemical sensor is to combine the identification of analytes and the signal that can be detected [48]. In past years, due to its extraordinary electrical and optical properties, the graphene has been employed in the field of biochemical sensor such as ionic species detection [49], glucose monitoring [50], microRNA detection [51], DNA detection [52], and folic acid detection [37]. However, reliable and scalable biochemical sensor manufacturing and transformation methods are in high demand to fill the existing gap between laboratory research and commercialization [53]. Direct laser writing will be an ideal fabrication technology and the LIG can be an alternative sensing material or device.

\section{Sensors for ions and small molecules}

Potentiometric ion sensing is one of the oldest and most well-known forms of chemical sensing that is useful for a variety of applications including clinical diagnostics. Kucherenko et al. reported LIG electrodes functionalized with ion-selective membranes for monitoring the concentrations of $\mathrm{NH}_{4}^{+}$and $\mathrm{K}^{+}$in urine samples. This electrochemical LIG sensor exhibits a broad sensing range $(0.1-150 \mathrm{mM}$ for $\mathrm{NH}_{4}{ }^{+}$and $0.3-150 \mathrm{mM}$ for $\mathrm{K}^{+}$) with high stability across a wide range of $\mathrm{pH}$ (3.5 to 9.0) in aqueous solutions [54]. 
Fig. 4 A Schematic diagram of preparing the P-doped LIG interdigitated array electrodes. Reprinted with permission from ref. [43], Copyright 2020 Elsevier Ltd. B Schematic diagram of preparing the LI-CdS-G@ ITO photoelectrode. Reprinted with permission from ref. [44], Copyright 2019 WILEY-VCH Verlag GmbH \& Co. KGaA, Weinheim
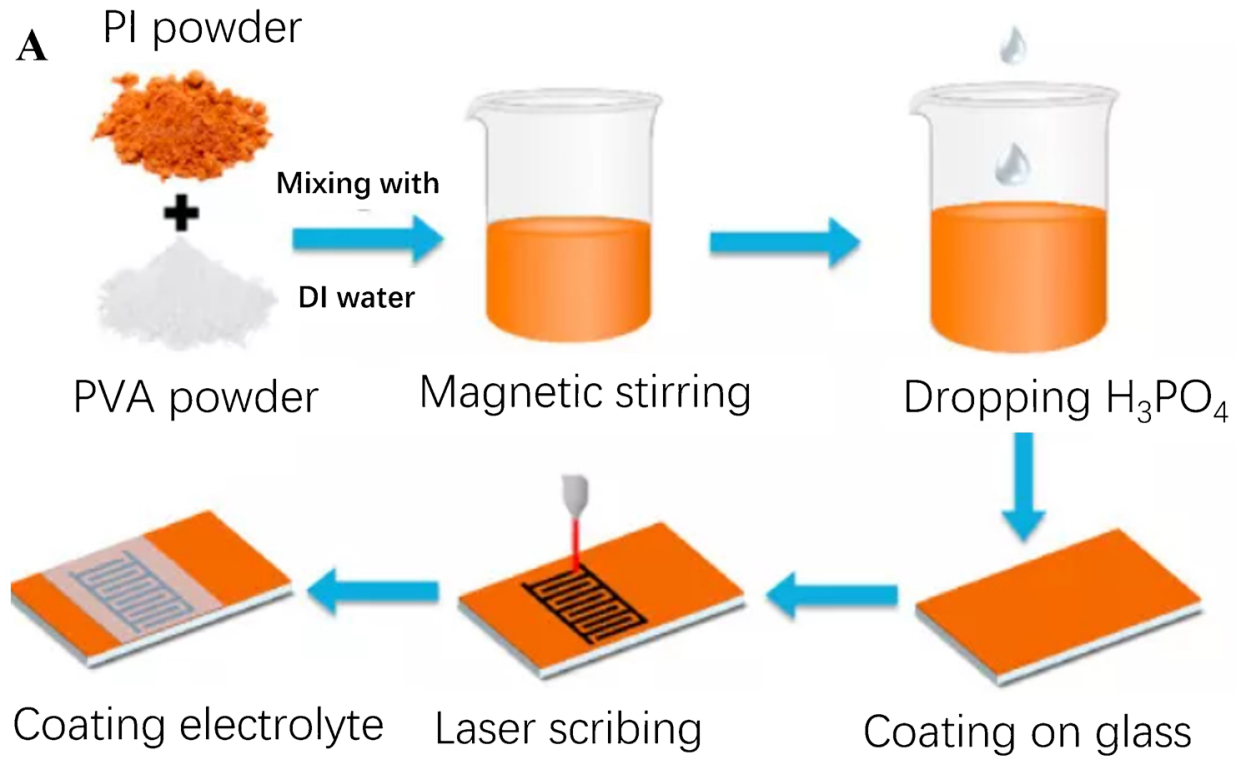

B

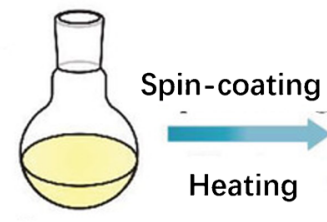

$\mathrm{Cd}^{2+}$-containing

PES mixture

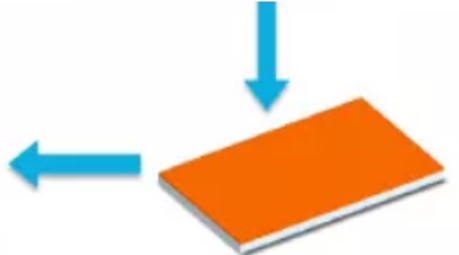

Coating on glass slide
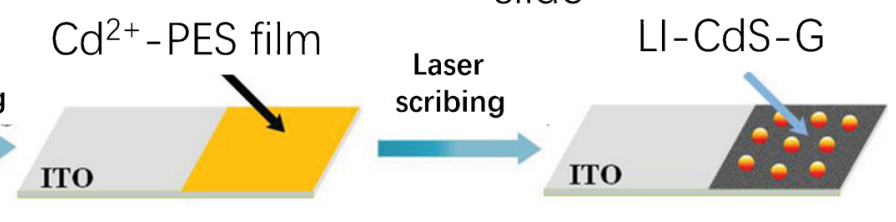

LI-CdS-G@ITO
Dopamine (DA) is an important information transmitter in the mammalian central nervous system. The continuous overproduction of DA can cause irritability, uncontrollable emotion, extreme hyperactivity, and rapid nerve reflex. Even very low levels can lead to Huntington's chorea or Parkinson's disease $[55,56]$. Hence, it is necessary to develop rapid, low-cost, and accurate detection devices for the DA. A Pt-Au nanoparticles (NPs) functionalized LIG/PDMS (polydimethylsiloxane) electrode was reported for detecting the DA in a neutral solution and in human urine [57]. The LIG-based sensor exhibited an excellent sensitivity of approximately $865.80 \mathrm{~mA} / \mathrm{mM} \mathrm{cm}^{-2}$ and a limit of detection (LOD) $75 \mathrm{nM}$. Meanwhile, it was demonstrated that it showed acceptable selectivity for interfering substances such as uric acid (UA) and ascorbic acid (AA).

The determination of urea is closely related to the human body's kidney function [58], cardiovascular function [59], and environment [60]. Sharma et al. [61] developed a LIG-based $\mathrm{pH}$ sensor for urea detection. The sensor is flexible and compatible with catheters. It can successfully detect urea concentrations as low as $10^{-4} \mathrm{M}$ and with the response time of less than $1 \mathrm{~min}$. By comparing the direct connection of urease on the surface of LIG and the electrodeposition of chitosan hydrogel film on the surface of LIG, it was found that the electrostatic and covalent immobilization strategy of chitosan can increase the amount of immobilized urease. These ureases can catalyze the hydrolysis of urea into $\mathrm{CO}_{2}$ and ammonia [62], which can be easily detected with the LIG-based $\mathrm{pH}$ sensor. This makes the large-scale usage of the urea sensor possible.

Diabetes is a major health concern in the modern society. The monitoring of the blood glucose is crucial to provide treatment and control plans for patients. Tehrani et al. reported an enzyme-free and sensitive glucose sensor based on $\mathrm{Cu}$ NCs (copper nanocubes)-decorated LIG [63]. In the glucose concentration range of $0.25 \mu \mathrm{M}$ to $4 \mathrm{mM}$, the sensor showed a linear response with a LOD of $250 \mathrm{nM}$ and an excellent sensitivity of $4532.2 \mu \mathrm{AmM}^{-1} \mathrm{~cm}^{2}$. The amperometric readout time was within $3 \mathrm{~s}$. The sensor was demonstrated to have a great potential for glucose detection in sweat, saliva, tears, and urine. The porous LIG with an abundance of crystallographic defects and large surface area enhances the electroplating process of the $\mathrm{Cu} \mathrm{NCs}$ (as the catalyst for oxidation of glucose) and increases loading of the highly reactive $\mathrm{Cu}$ NCs as well as accessibility of glucose molecules. N-doped LSG electrodes decorated with MXene/Prussian blue $\left(\mathrm{Ti}_{3} \mathrm{C}_{2} \mathrm{Tx} / \mathrm{PB}\right)$ composite via a simple spray-coating process were designed for sensitive detection of three analytes including glucose, lactate, and ethanol [64]. The $\mathrm{Ti}_{3} \mathrm{C}_{2} \mathrm{Tx} / \mathrm{PB}$-modified N-LSG electrodes were functionalized with corresponding catalytic enzymes. The enzyme/ $/ \mathrm{Ti}_{3} \mathrm{C}_{2} \mathrm{Tx} / \mathrm{PB} / \mathrm{N}-\mathrm{LSG}$ electrodes exhibited 
remarkably enhanced electrochemical activity toward the detection of these analytes with a performance on par with previously reported on-chip carbon-based biosensors.

The detection of other small molecules, macromolecules, and cells based on LIG is summarized in Table 1 .

\section{Sensors for nucleic acids}

MicroRNAs (miRNAs) are a class of small noncoding RNAs (about 21-23 nucleotides in length) which regulate gene expression at translational or posttranslational levels. They were demonstrated as a type of significant biomarkers for various diseases [65]. Recently, a LIGbased biosensor for preeclampsia specific miRNA detection was reported [40]. The authors demonstrated that the nitrogen $(\mathrm{N})$ atoms in the precursor PI have been partially incorporated into the LIG in the form of polyrolic $\mathrm{N}$ (1.6 to $4.4 \%$ ) and graphitic $\mathrm{N}$ (from 2.4 to $4.5 \%$ ). The self-N-doped porous LIG possesses enhanced conductivity as an electrochemical sensor and improved sensitivity to nucleic acids. Combining with the miRNA extraction and magnetic isolation procedures, the limit of detection (LOD) of the miRNA was down to $10 \mathrm{fM}$ and it showed an excellent reproducibility. The study suggested that the self-N-doped LIG has great potential as a simple and lowcost biosensor platform for the detection and analysis of nucleic acids.

\section{Sensors for protein}

Thrombin is a vital therapeutic biomarker for diseases associated with coagulation abnormalities. It is a serine protease which can convert soluble fibrinogen into insoluble strands of fibrin [66]. Recently, a reliable and sensitive LIG biosensor functionalized by aptamer was demonstrated to thrombin in serum [67]. The LIG electrodes with enhanced electrochemically active area were manufactured by a laser direct-write process on PI foils. A universal immobilization approach is established by anchoring 1-pyrenebutyric acid to the LIG and subsequently

Table 1 Overview of various biochemical sensors based on the LIG

\begin{tabular}{|c|c|c|c|c|c|c|c|}
\hline $\begin{array}{l}\text { Sensor configu- } \\
\text { ration }\end{array}$ & $\begin{array}{l}\text { Functionaliza- } \\
\text { tion method }\end{array}$ & Matrix & Analyte & Sensitivity & $\begin{array}{l}\text { Concentration } \\
\text { range }\end{array}$ & LOD & Ref \\
\hline LIG-ISEs & Ionophores & Urine & $\begin{array}{l}\mathrm{NH}_{4}^{+} \\
\mathrm{K}^{+}\end{array}$ & $\begin{array}{l}51 \mathrm{mV} \mathrm{dec}^{-1} \\
53 \mathrm{mV} \mathrm{dec}^{-1}\end{array}$ & $\begin{array}{l}0.1-150 \mathrm{mM} \\
0.3-150 \mathrm{mM}\end{array}$ & $\begin{array}{l}30 \mu \mathrm{M} \\
100 \mu \mathrm{M}\end{array}$ & [54] \\
\hline Pt-LIG & Enzyme & DMEM & $\mathrm{H}_{2} \mathrm{O}_{2}$ & $248.4 \mathrm{~mA} \mathrm{mM}^{-1} \mathrm{~cm}^{-2}$ & $0.5-5 \mathrm{mM}$ & $0.1 \mathrm{mM}$ & [74] \\
\hline $\begin{array}{l}\text { LIG/PDMS } \\
\text { electrode }\end{array}$ & Pt-Au NPs & Human urine & Dopamine & $865.80 \mathrm{~mA} \mathrm{mM}^{-1} \mathrm{~cm}^{-2}$ & $\begin{array}{l}0.95-3.45 \mathrm{mM} \\
5-30 \mathrm{mM}\end{array}$ & $75 \mathrm{nM}$ & [57] \\
\hline PEDOT-LSG & NA & NA & Dopamine & $0.220 \pm 0.011 \mu \mathrm{A} \mu \mathrm{M}^{-1}$ & $1-150 \mu \mathrm{M}$ & $0.33 \mu \mathrm{M}$ & [75] \\
\hline LIG/chitosan & Urease enzyme & NA & Urea & NA & NA & $0.1 \mathrm{mM}$ & [61] \\
\hline LIG & $\mathrm{Cu} \mathrm{NCs}$ & NA & Glucose & $4532.2 \mu \mathrm{A} \mathrm{mM}^{-1} \mathrm{~cm}^{2}$ & $0.25 \mu \mathrm{M}-4 \mathrm{mM}$ & $250 \mathrm{nM}$ & [63] \\
\hline LIG fibers & Au@Ni & Sweat & Glucose & $3500 \mu \mathrm{A} \mathrm{mM}^{-1} \mathrm{~cm}^{-2}$ & $0-30 \mathrm{mM}$ & $1.5 \mu \mathrm{M}$ & [76] \\
\hline $\begin{array}{l}\text { (PEDOT:PSS)- } \\
\text { LIG }\end{array}$ & $\mathrm{Pt} @ \mathrm{Pd}$ & Perspiration & Glucose & NA & $10 \mu \mathrm{M}-9200 \mu \mathrm{M}$ & $3 \mu \mathrm{M}$ & [77] \\
\hline $\begin{array}{l}\mathrm{Ti}_{3} \mathrm{C}_{2} \mathrm{Tx} / \mathrm{PB} / \mathrm{N}- \\
\mathrm{LSG}\end{array}$ & Enzyme & Sweat & $\begin{array}{l}\text { Glucose } \\
\text { Lactate } \\
\text { Alcohol }\end{array}$ & $\begin{array}{l}49.2 \mu \mathrm{A} \mathrm{mM}^{-1} \mathrm{~cm}^{-2} \\
21.6 \mu \mathrm{Am}^{-1} \mathrm{~cm}^{-2} \\
5.78 \mu \mathrm{Am}^{-1} \mathrm{~cm}^{-2}\end{array}$ & $\begin{array}{l}10 \mu \mathrm{M}-5.3 \mathrm{mM} \\
0-20 \mathrm{mM} \\
0-50 \mathrm{mM}\end{array}$ & $\begin{array}{l}0.3 \mu \mathrm{M} \\
0.5 \mu \mathrm{M} \\
\text { NA }\end{array}$ & [64] \\
\hline LIG & Antibody-PPA & Sweat & Cortisol & NA & $0.43-50.2 \mathrm{ng} / \mathrm{mL}$ & $0.22 \mu \mathrm{M}$ & [78] \\
\hline LIG & MIP & Aquaculture & CAP & NA & $1 \mathrm{~nm}-10 \mathrm{mM}$ & $0.62 \mathrm{nM}$ & [22] \\
\hline LIG & $\mathrm{Cu}-\mathrm{DAO}$ & Food & Biogenic amines & $23.3 \mu \mathrm{A} \mathrm{mM^{-1 }}$ & NA & $11.6 \mu \mathrm{M}$ & [79] \\
\hline N-doped LIG & NA & NA & MicroRNA & NA & NA & $10 \mathrm{fM}$ & [40] \\
\hline LSG & Aptamer & Serum & Thrombin & $-2.41 \pm 0.16 \mu \mathrm{A} \mathrm{cm}^{-2}$ & $1-100 \mathrm{pM}$ & $1 \mathrm{pM}$ & [67] \\
\hline $\begin{array}{l}\text { PtNPs/PAAMI- } \\
\text { LAG }\end{array}$ & Antibody & Serum & $\mathrm{IgG}$ & NA & $\begin{array}{l}0.012-15 \text { and } \\
15-352 \mathrm{ng} \mathrm{mL}^{-1}\end{array}$ & $6 \mathrm{pg} \mathrm{mL}^{-1}$ & [69] \\
\hline AuNSs-LIG & Antibody & Serum & $\begin{array}{l}\text { SARS-CoV-2 S } \\
\text { protein }\end{array}$ & NA & $5.0-500 \mathrm{ng} \mathrm{mL}^{-1}$ & $2.9 \mathrm{ng} \mathrm{mL}^{-1}$ & [70] \\
\hline LIG & Antibody & Chicken broth & Salmonella & NA & $\begin{array}{l}25 \text { to } \\
10^{5} \mathrm{CFU} \mathrm{mL}^{-1}\end{array}$ & $13 \pm 7 \mathrm{CFU} \mathrm{mL}{ }^{-1}$ & [80] \\
\hline
\end{tabular}

$A$ u NSs gold nanostructure; $C A P$ chloramphenicol; $D A O$ diamine oxidase; $D M E M$ Dulbecco's Modified Eagle's Medium; $E B T$ eriochrome black T; $L A G$ laser-ablated graphene; $L S G$ laser-scribed graphene; $M I P$ molecular imprinted polymers; $N A$ not available; $N C s$ nanocubes; $N P s$ nanoparticles; PAAMI polyelectrolyte polyallylamine; PEDOT:PSS poly(3,4-ethylene dioxythiophene)-poly(styrene sulfonate);PPA $1 \mathrm{H}-$ pyrrole propionic acid; $P V C$ polyvinyl chloride; ISEs ion-selective electrodes 
covalently attaching an aptamer against the thrombin as a specific bioreceptor to the carboxyl groups (Fig. 5). The incubation time of the aptamer and the thrombin is just $30 \mathrm{~min}$. The developed LIG biosensor showed relatively low LOD of $1 \mathrm{pM}$ in buffer and $5 \mathrm{pM}$ in the serum. The resulting sensitivity was $-2.41 \pm 0.16 \mu \mathrm{A} \cdot \mathrm{cm}^{-2}$ per logarithmic concentration unit.

Immunoglobulin (IgG) plays a critical role in certain disease. The abnormal of the IgG concentration may affect the function of organs and cause a failure to prevent infections [68]. Park's group reported an electrochemical immunosensor using cationic polyelectrolyte polyallylamine (PAAMI)-anchored LAG as the electrode [69]. The addition of the PAAMI gave abundant clipping sites for fixing antibodies through introducing the amino group. Meanwhile, it increases the stability of the LAG flakes by electrostatic adsorption. Then, Pt nanoparticles were employed to decorate the PAAMI@LAG by the electrodeposition method and thus offered a fast electron transfer rate. The developed immunosensor was utilized to detect the $\operatorname{IgG}$ as a proof of concept. Under optimized conditions, the immunosensor showed a linear range of $0.012-15$ and $15-352 \mathrm{ng} \mathrm{mL}^{-1}$ with a LOD of $6 \mathrm{pg} \mathrm{mL} \mathrm{L}^{-1}$.

The global pandemic caused by the severe acute respiratory syndrome coronavirus 2 (SARS-CoV-2) continues. Instant detection and timely isolation are still the most effective management and control strategy. Hence, there is the urgent need for developing rapid, accurate, and lowcost diagnostic devices. An electrochemical immunosensor based on three-dimensional (3D) gold nanostructures decorated LSG was reported for the coronavirus disease 2019 (COVID-19) diagnosis [70]. This electrode was functionalized with antibodies to the SARS-CoV-2 spike
(S) antigen following a proper surface modification step (Fig. 6). The analytical performance of the electrochemical immunosensor was evaluated applying the standard solution of $\mathrm{S}$ protein in the range of $5.0-500 \mathrm{ng} / \mathrm{mL}$ with a LOD of $2.9 \mathrm{ng} / \mathrm{mL}$. The LSG-based electrochemical immunosensor can offer faster readout time compared to commercial diagnostic tools and provide a promising alternative method for affordable and rapid POCT devices.

\section{Sensors for cells}

Graphene has a relatively large surface area and can provide a stable interface for eucaryotic cells and microorganisms $[71,72]$. A study reported the usage of LSG as a novel electrode material for cell monitoring based on the impedance measurement [73]. The prepared LSG electrodes showed 25 times larger interface capacitance than standard flat gold electrodes because of their foam-like 3D topography. The LSG electrodes can be prepared in customized sizes from micrometer to centimeter with tunable surface topography and they can be easily integrated to by roll-to-roll manufacturing lines. Furthermore, the LSG electrodes were demonstrated to have excellent compatibility for cell attachment.

A LIG-based electrochemical immunosensor was developed for the detection of Salmonella typhimurium. The LIG electrodes were fabricated by laser induction on the polyimide film in ambient conditions, which circumvents the need for high-temperature, vacuum environment, and metal seed catalysts commonly associated with graphene-based electrodes fabricated via chemical vapor deposition processes. After functionalization with Salmonella antibodies, the LIG biosensors were able to detect live Salmonella

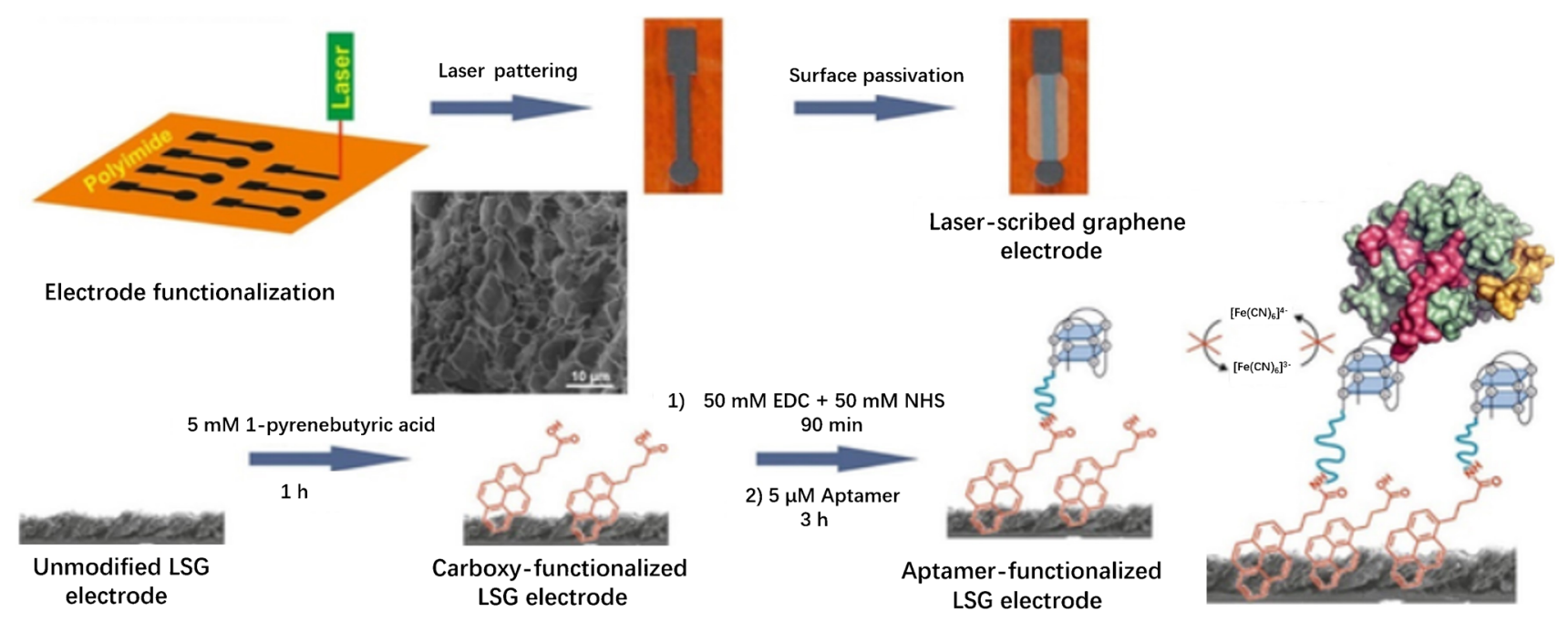

Fig. 5 Schematic diagram of preparing LIG-based aptamer interdigitated array electrodes. Reprinted with permission from ref. [67], Copyright 2017 American Chemical Society 
Fig. 6 Schematic diagram of preparing LSG-based immuprotein detection. Reprinted with permission from ref. [70], Copyright 2021 American Chemical Society nosensor for SARS-CoV-2 S

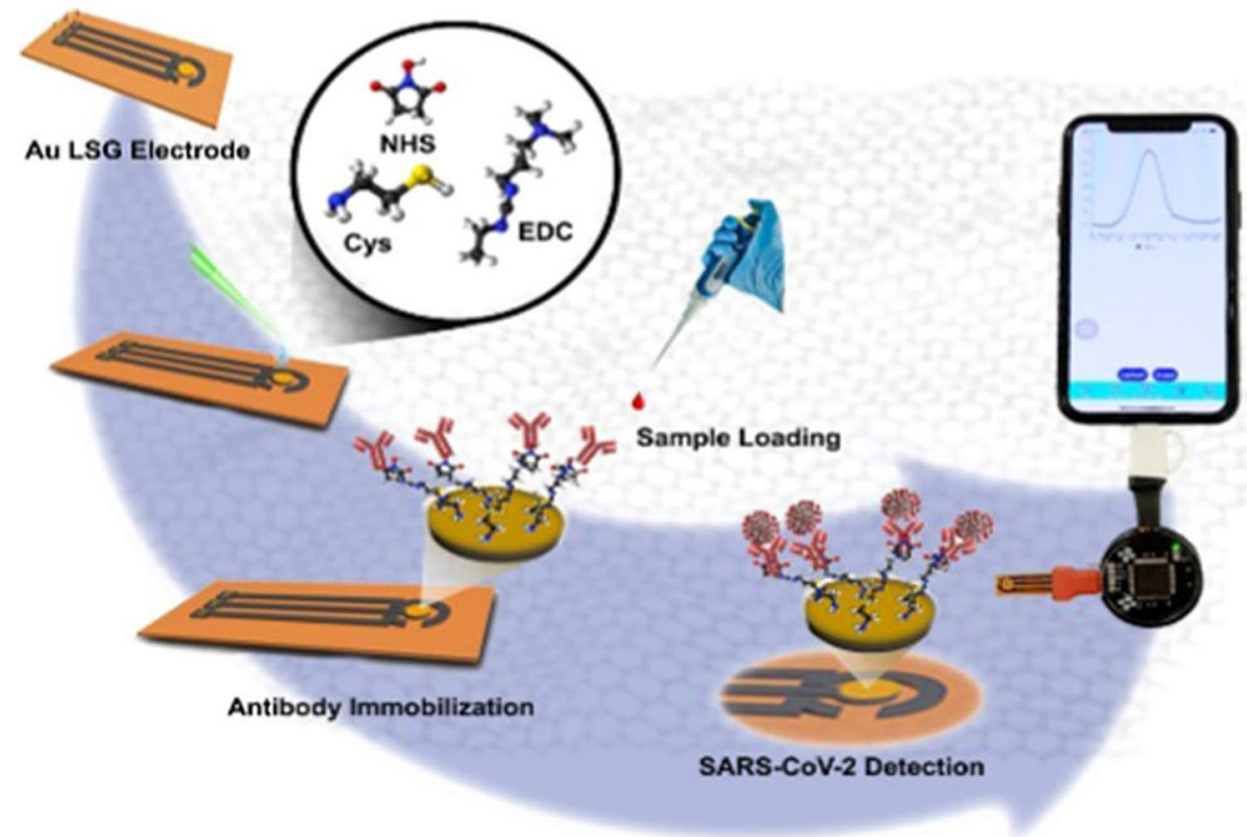

in chicken broth across a wide linear range of 25 to $10^{5} \mathrm{CFU} \mathrm{mL} \mathrm{m}^{-1}$ and with a low LOD of $13 \pm 7 \mathrm{CFU} \mathrm{mL}^{-1}$. These results were acquired with an average response time of $22 \mathrm{~min}$ without the need for sample preconcentration or redox labeling techniques.

\section{Sensors for physical physiological markers}

The monitoring of physical physiological signals (such as the human humidity and breathing rhythm) has a critical role in chronic disease management (CCM), elderly care management, and personalized medicine. Interdigitated array electrodes are mostly used transducers of electrical/ electrochemical sensors [81]. Recently, LIG-based interdigitated array electrodes (IDEA) were developed by laser direct writing technology [82]. The graphene oxide (GO)-coated IDEA was applied to develop a humidity sensor with low hysteresis, high sensitivity (3215.25 pF/\% RH), and longterm stability (variation less than 1\%). The IDEA images shown in Fig. 7A-C are cross-sectional images of electrodes without and with graphene oxide layer, respectively. GO was introduced as a sensitive material because of its unique 2D structure and super-permeability to $\mathrm{H}_{2} \mathrm{O}$ molecules. Under low humidity conditions, $\mathrm{H}_{2} \mathrm{O}$ molecules bond to active sites of GO by forming double hydrogen bonds, and with the humidity increasing, $\mathrm{H}_{2} \mathrm{O}$ molecules bond to active sites of $\mathrm{GO}$ in the single hydrogen bond. Hence, it greatly increases the mobility of $\mathrm{H}_{2} \mathrm{O}$ molecules. The increased activity induced $\mathrm{H}_{2} \mathrm{O}$ molecules to move, and the moving $\mathrm{H}_{2} \mathrm{O}$ molecules are ionized into hydrogen ions in an electric field, which can act as charge carriers. Then, they move on the GO layer, resulting in a significant increase in capacitance under high humidity conditions. Thanks to its flexibility, the LIG-IDEA-based humidity sensor could be easily employed as a wearable device for the in situ monitoring of the human breath humidity (the real object is shown in Fig. 7D). The results of human humidity and breathing rhythm are shown in Fig. 7E and F, which shows that the LIG-IDEA humidity sensor can detect breathing rhythm very well.

A temperature sensor and a flow sensor were developed by Marengo and coworkers based on the LIG [83]. The resistance of the temperature sensor reduces with the temperature increase. Thanks to the piezoresistive properties of the LIG, a flow sensor was fabricated. After a patterned LIG was engraved on the PI film, the copper tape was pasted on both contact points and conductive silver glue was used to connect the copper and the LIG, which can improve the stability of the contact points. Then, polydimethylsiloxane (PDMS) was evenly coated on the electrode to prevent the LIG electrode from being interfered by ions. The results revealed that the LIG-based flow sensor has an excellent performance to response the flow rates $(0,1500,2500,3500,4500 \mathrm{rpm})$.

\section{Wearable devices}

In recent years, wearable sensing devices have attracted more attention, such as sweat biosensors [84] and electronic skin [85]. Graphene holds great promise for developing soft and flexible electronic products. The LIG artificial physical 

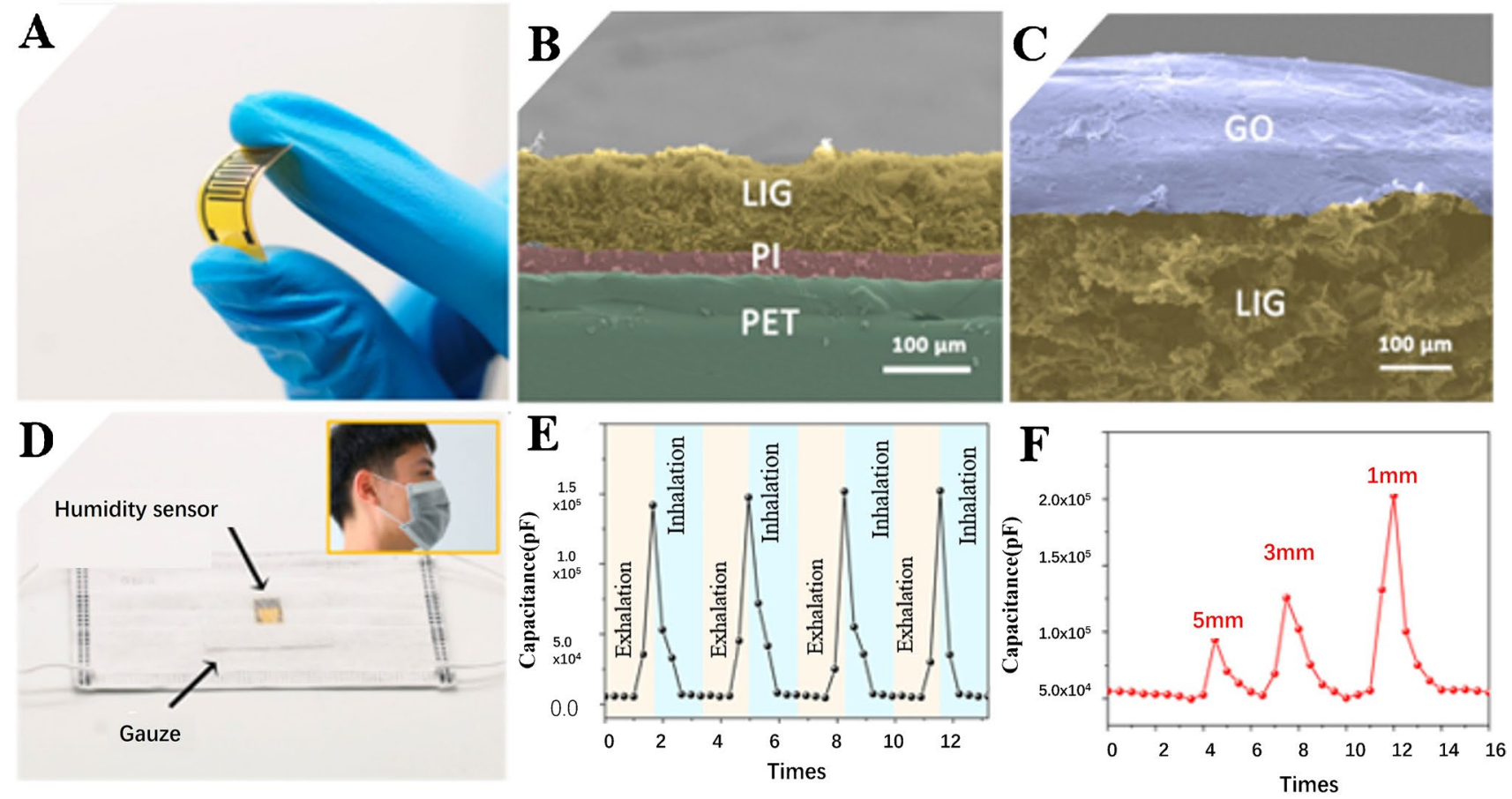

Fig. 7 A The image of the LIG interdigitated array electrodes. B Side view of the LIG electrodes. C SEM image of the cross-section of the electrodes with GO coated. D The application of the LIG-based sensor in face masks. E The capacitive response of the sensor to human

physiological device has the advantages of one-step molding, high efficiency, brilliant flexibility, and low cost, and has a broad and unexceptionable application. Multi-functional instruments based on LIG show great potential in medical monitoring and timely warning. Based on the excellent mechanical and thermal effects of graphene, scholars have proposed an integrated multi-functional device for sensing and alarm on the basis of double-layer asymmetric structure. When the detectable signal reaches the threshold conditions for real-time measurement by the ultrasensitive strain sensor, it can generate enough heat to warn the body. Advances in laser processing technology will definitely drive the rapid development of graphene electronic skin and wearable devices.

Tao and coworkers demonstrated that LIG has a high thermal conductivity and a low heat capacity, which makes it an ideal material for thermal sound sources [86]. Moreover, the porous structure of the LIG is sensitive to weak vibration and is suitable for sound detection. When working as a sound source, the LIG artificial throat can produce broadband sound in frequencies ranging from $100 \mathrm{~Hz}$ to $40 \mathrm{kHz}$. A thinner LIG will produce a higher sound pressure level (SPL). As a sound detector, the LIG artificial throat exhibits unique responses to different sounds and throat breathing. F Capacitance response based on different distances between face and the sensor. Reprinted with permission from ref. [82], Copyright 2020 Elsevier B.V

vibration modes. LIG can identify buzzes, screams, and coughs with different pitch and volume. When the device applies a low bias voltage, the vibration of the throat will cause changes in the device resistance, resulting in current fluctuations. The artificial throat also can produce sound. When an alternating voltage was applied to the device, the periodic joule heat causes the air to expand, resulting in sound waves. Therefore, the device can act as both sound source and detector. Cough, buzzing, or screeching can cause vibrations in the larynx, which can be detected by the LIG artificial throat, and the LIG artificial throat produces a controlled sound accordingly (Fig. 8A and B). When graphene is deformed, its resistance will also change [87, 88]. Drawing lessons from the principle of the above sound sensor, we can design some equipment according to some deformations that must occur in the daily life activities of the human body, such as heart pulse, breathing rhythm, and finger movement. Different gestures can cause different deformations in different positions of the hand. Placing multiple sensors on the hand may enable communication between aphasia and normal people. Park et al. improved the stretchability of LIG and made wearable devices for monitoring glucose in sweat, $\mathrm{pH}$ value, and electrocardiogram [89]. Wearable electrochemical-physiological sensors 

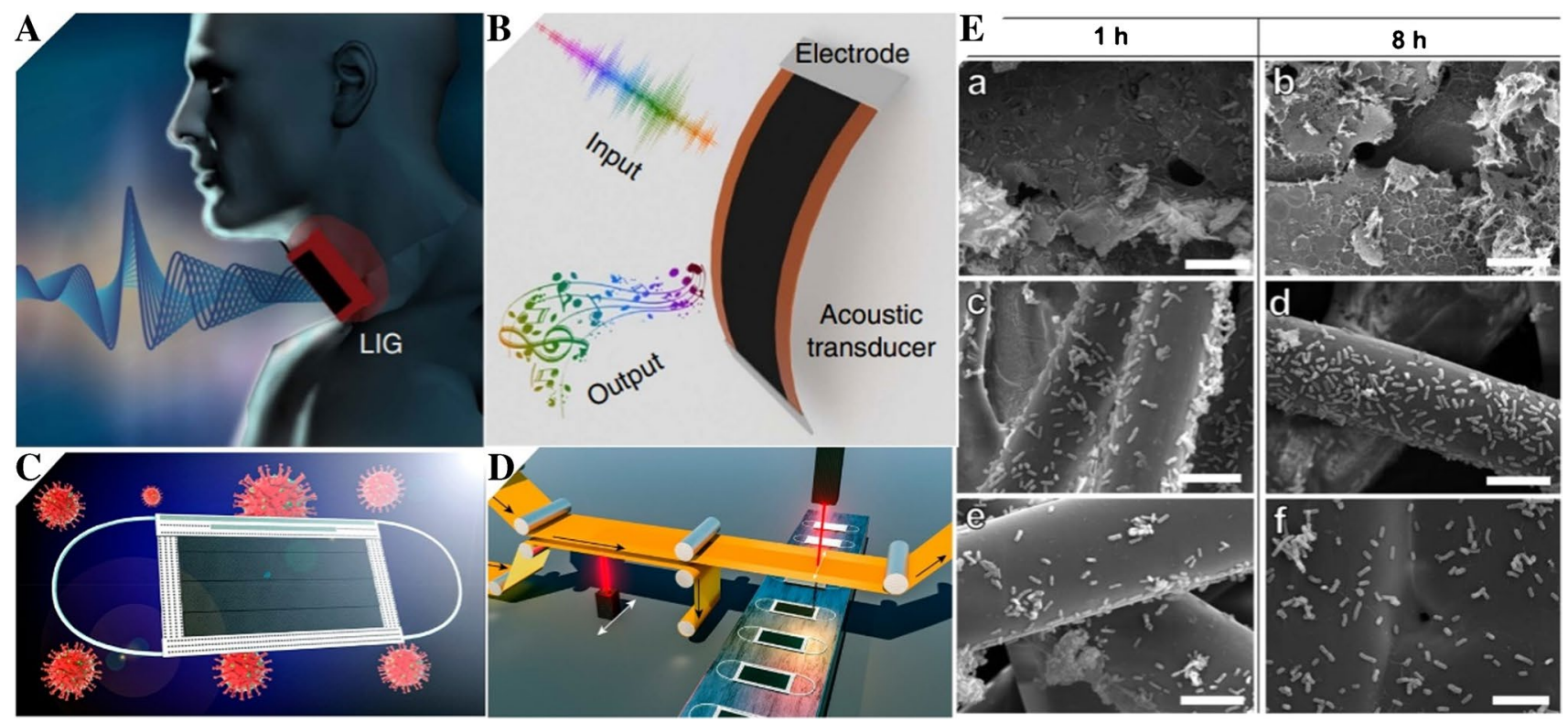

Fig. 8 A LIG has the ability of emitting and detecting sound in one device. B The LIG-based artificial throat can detect the movement of throat and generate controllable sound. Reprinted with permission from ref. [11], Copyright 2017 Springer Nature. C Anti-virus mask based on graphene. D The general production process of anti-viral graphene masks. Reprinted with permission from ref. [90], Copy- right 2020 American Chemical Society. E Comparison of antibacterial ability between LIG, ACF, and MBF. SEM images of ( $a, b)$ LIG, (c, d) ACF, and (e, f) MBF after 1-h and 8-h incubation. Reprinted with permission from ref. [91], Copyright 2020 American Chemical Society are integrated, pointing out the direction for future integrated devices.

Interestingly, LIG-based masks were developed which can be used for sterilization. Scholars processed the graphene inside the mask to achieve a super-hydrophobic state, which can kill virus under the sunlight [90]. The schematic diagram and production process of the antibacterial LIG-based mask are shown in the Fig. 8C and D. Another research group reported LIG-based face masks which can kill bacteria by its photothermal effect [91]. By comparing with conventional masks on the market, the bacteria on conventional masks are still alive after $8 \mathrm{~h}$, while the sterilization rate of the LIG-based mask reached an amazing number $99.998 \%$ within $10 \mathrm{~min}$. The antibacterial abilities of LIG, activated carbon fiber (ACF), and melt-blown fabrics (MBF) are shown in the Fig. 8E. The LIG-based mask can block and kill germs more effectively, making the mask safer and more beneficial to the natural environment.

In daily life, wearable devices with timely alarm functions are expected to help people avoid potential dangers. At present, various types of flexible wearable sensor devices are widely studied and applied to different physiological signal monitoring. However, to achieve the early warning function, they usually need to integrate additional early warning devices, such as light-emitting diodes and buzzers, which will increase the complexity of the system. Scholars have proposed a method based on a two-layer asymmetric pattern structure by combining the mechanical and thermal properties of porous graphene [92]. The porous graphene of different patterns is transferred to a flexible and stretchable PDMS substrate, and the device is lifted by patterning. At the same time, it is proposed to use device heating for direct warning, and finally realize the application of integrated sensing and alarm multi-functional flexible devices. Figure 9A presents schematic diagram of integrated device synthesis, Fig. 9B shows a schematic diagram of principle, Fig. 9C, $\mathrm{D}$, and $\mathrm{E}$ describe the mechanical performance, pulse monitoring performance, and thermal performance of the developed sensor, respectively. This research provided a novel method for developing multi-functional wearable devices which would be beneficial for health monitoring and timely warning. Figure 9F shows the device has good performance for the temperature warning.

\section{Conclusions and perspectives}

This review mainly discusses the application of LIG in medical sensors. There is no doubt that the LIG has drawn a great attention from biomedical sensor field and it is making 
Fig. 9 A Schematic diagram of the preparation of LIG-based wearable device, $\mathbf{B}$ schematic diagram of the measuring principle, $\mathbf{C}$ mechanical performance, $\mathbf{D}$ pulse monitoring performance, $\mathbf{E}$ thermal performance, and $\mathbf{F}$ early warning test results of the developed sensor. Reprinted with permission from ref. [92], Copyright 2020 American Chemical Society

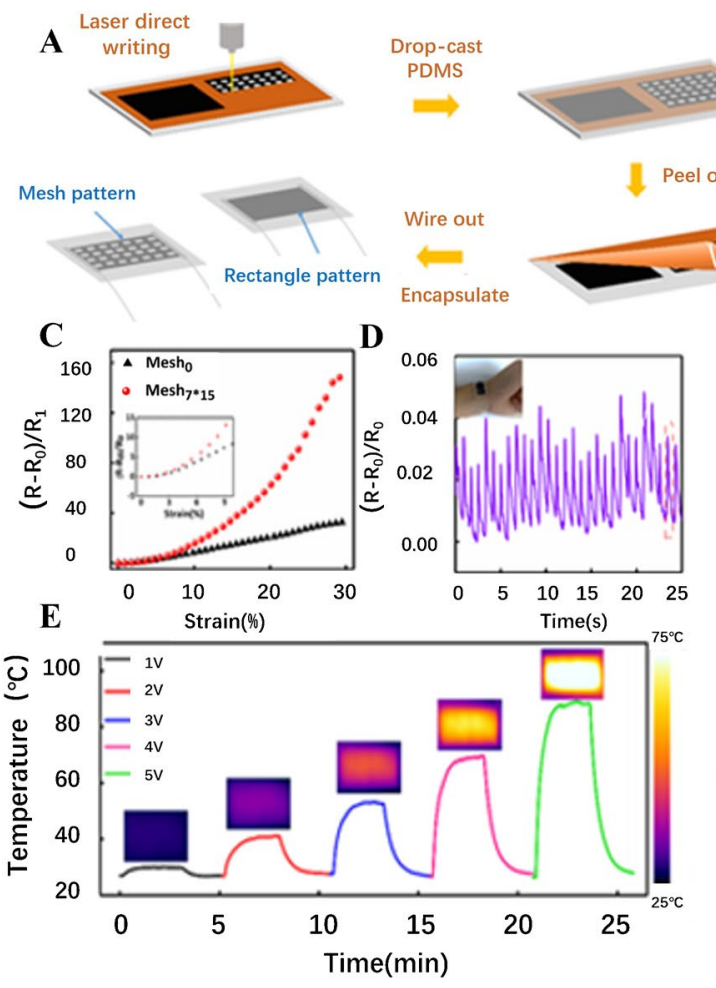

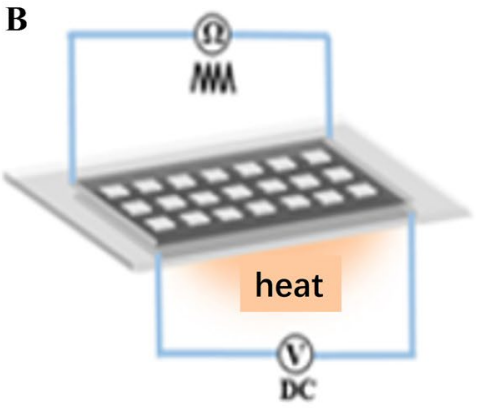

F

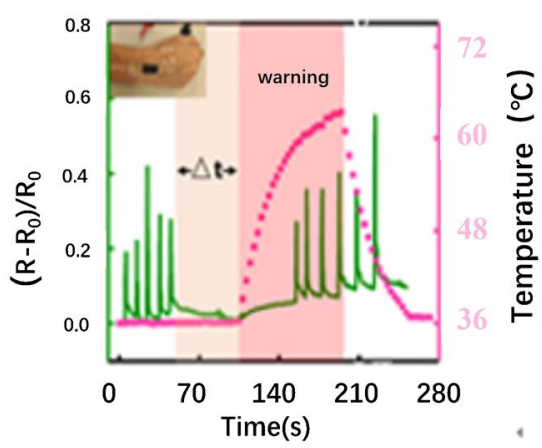

great strides forward. However, the study in this field still stays in the beginning stage. It still faces challenges. The interactions between lasers and polymer materials are a nonequilibrium, nonlinear, and multi-scale process. At present, the mechanism of the interaction between laser and polymer materials is still not fully explored. It is necessary to reveal the interaction mechanism between photons and lattices or electrons. Besides, the LIG is not robust enough as a substrate for electrophoretic coating or surface-enhanced Raman spectroscopy (SERS) because of the porous graphene that may be peeled off or scorched under a relatively high voltage or laser.

There are plenty of ways to extend this research area. The performance of LIG, such as stability, conductivity, and electrocatalytic activity, can be further improved by controlling the morphology, porosity, and surface functionalization. Optimizing its composition through doping heteroatom is an imaginative approach for developing more robust LIG-based medical sensors. In addition, current readout method using LIG as transducer is limited, and it mainly relies on the electrochemical measurement. Other readout methods, such as SERS, fluorescence, and quartz crystal microbalance (QCM), should be explored and demonstrated. Further development of LIG-based biosensors, especially wearable biomedical sensors, for detecting biomarkers (including RNAs, DNAs, proteins, virus, and whole cells) is highly encouraged. In all, it can be concluded that continued efforts in graphene laser direct manufacturing will drive rapid advances in the biomedical fields.

Funding The study was supported by the National Natural Science Funds of China (81871567, 82030065 and 82102502) and China Postdoctoral Science Foundation (2021M693763).

\section{Declarations}

Conflict of interest The authors declare no competing interests.

\section{References}

1. Cui F, Zhou Z, Zhou HS (2020) Review-measurement and analysis of cancer biomarkers based on electrochemical biosensors. J Electrochem Soc 167:037525

2. Pendley BD, Lindner E (2017) Medical sensors for the diagnosis and management of disease: the physician perspective. ACS Sensors 2:1549-1552

3. Cui F, Zhou HS (2020) Diagnostic methods and potential portable biosensors for coronavirus disease 2019. Biosens Bioelectron 165:112349

4. Maduraiveeran G, Sasidharan M, Ganesan V (2018) Electrochemical sensor and biosensor platforms based on advanced nanomaterials for biological and biomedical applications. Biosens Bioelectron 103:113-129

5. Su S, Sun Q, Gu X, Xu Y, Shen J, Zhu D, Chao J, Fan C, Wang L (2019) Two-dimensional nanomaterials for biosensing applications. TrAC Trends Anal Chem 119:115610 
6. Zhang L, Liang J, Huang Y, Ma Y, Wang Y, Chen Y (2009) Size-controlled synthesis of graphene oxide sheets on a large scale using chemical exfoliation. Carbon 47:3365-3368

7. Luo J, Cote LJ, Tung VC, Tan AT, Goins PE, Wu J, Huang J (2010) Graphene oxide nanocolloids. J Am Chem Soc 132:17667-17669

8. Chen D, Tang L, Li J (2010) Graphene-based materials in electrochemistry. Chem Soc Rev 39:3157-3180

9. Ambrosi A, Chua CK, Latiff NM, Loo AH, Wong CHA, Eng AYS, Bonanni A, Pumera M (2016) Graphene and its electrochemistry - an update. Chem Soc Rev 45:2458-2493

10. Chauhan N, Maekawa T, Kumar DNS (2017) Graphene based biosensors-accelerating medical diagnostics to new-dimensions. J Mater Res 32:2860-2882

11. Tao L-Q, Tian H, Liu Y, Ju Z-Y, Pang Y, Chen Y-Q, Wang D-Y, Tian X-G, Yan J-C, Deng N-Q, Yang Y, Ren T-L (2017) An intelligent artificial throat with sound-sensing ability based on laser induced graphene. Nat Commun 8:14579

12. Chen S, Jiang K, Lou Z, Chen D, Shen G (2018) Recent developments in graphene-based tactile sensors and e-skins. Adv Mater Technol 3:1700248

13. Lim S, Son D, Kim J, Lee YB, Song JK, Choi S, Lee DJ, Kim JH, Lee M, Hyeon T (2015) Transparent and stretchable interactive human machine interface based on patterned graphene heterostructures. Adv Funct Mater 25:375-383

14. Zhang Q, Tan L, Chen Y, Zhang T, Wang W, Liu Z, Fu L (2016) Human-like sensing and reflexes of graphene-based films. Adv Sci 3:1600130

15. Lin J, Peng Z, Liu Y, Ruiz-Zepeda F, Ye R, Samuel EL, Yacaman MJ, Yakobson BI, Tour JM (2014) Laser-induced porous graphene films from commercial polymers. Nat Commun 5:1-8

16. Ye R, James DK, Tour JM (2019) Laser-induced graphene: from discovery to translation. Adv Mater 31:1803621

17. Lahcen AA, Rauf S, Beduk T, Durmus C, Aljedaibi A, Timur S, Alshareef HN, Amine A, Wolfbeis OS, Salama KN (2020) Electrochemical sensors and biosensors using laser-derived graphene: a comprehensive review. Biosens Bioelectron 168:112565

18. Chyan Y, Ye R, Li Y, Singh SP, Arnusch CJ, Tour JM (2018) Laser-induced graphene by multiple lasing: toward electronics on cloth, paper, and food. ACS Nano 12:2176-2183

19. Singh SP, Li Y, Zhang J, Tour JM, Arnusch CJ (2018) Sulfurdoped laser-induced porous graphene derived from polysulfoneclass polymers and membranes. ACS Nano 12:289-297

20. Han X, Ye R, Chyan Y, Wang T, Zhang C, Shi L, Zhang T, Zhao Y, Tour JM (2018) Laser-induced graphene from wood impregnated with metal salts and use in electrocatalysis. ACS Appl Nano Mater 1:5053-5061

21. Huang L, Su J, Song Y, Ye R (2020) Laser-induced graphene: en route to smart sensing. Nanomicro Lett 12:1-17

22. Cardoso AR, Marques AC, Santos L, Carvalho AF, Costa FM, Martins R, Sales MGF, Fortunato E (2019) Molecularly-imprinted chloramphenicol sensor with laser-induced graphene electrodes. Biosens Bioelectron 124:167-175

23. Carvalho AF, Fernandes AJ, Leitão C, Deuermeier J, Marques AC, Martins R, Fortunato E, Costa FM (2018) Laser-induced graphene strain sensors produced by ultraviolet irradiation of polyimide. Adv Funct Mater 28:1805271

24. Zhang Z, Song M, Hao J, Wu K, Li C, Hu C (2018) Visible light laser-induced graphene from phenolic resin: a new approach for directly writing graphene-based electrochemical devices on various substrates. Carbon 127:287-296

25. Soares RR, Hjort RG, Pola CC, Parate K, Reis EL, Soares NF, McLamore ES, Claussen JC, Gomes CL (2020) Laser-induced graphene electrochemical immunosensors for rapid and label-free monitoring of Salmonella enterica in chicken broth. ACS Sens 5:1900-1911
26. Cai J, Lv C, Watanabe A (2016) Laser direct writing of highperformance flexible all-solid-state carbon micro-supercapacitors for an on-chip self-powered photodetection system. Nano Energy 30:790-800

27. Dukes JD, Whitley P, Chalmers AD (2011) The MDCK variety pack: choosing the right strain. BMC Cell Biol 12:1-4

28. Ye R, Peng Z, Wang T, Xu Y, Zhang J, Li Y, Nilewski LG, Lin J, Tour JM (2015) In situ formation of metal oxide nanocrystals embedded in laser-induced graphene. ACS Nano 9:9244-9251

29. Griesche C, Hoecherl K, Baeumner AJ (2021) Substrate-independent laser-induced graphene electrodes for microfluidic electroanalytical systems. ACS Appl Nano Mater 4:3114-3121

30. Lahcen AA, Rauf S, Beduk T, Durmus C, Aljedaibi A, Timur S, Alshareef HN, Amine A, Wolfbeis OS, Salama KN (2020) Electrochemical sensors and biosensors using laser-derived graphene: a comprehensive review. Biosens Bioelectrons 168:112565

31. Ye R, James DK, Tour JM (2019) Laser-induced graphene: from discovery to translation. Adv Mater 31:1803621

32. You R, Liu Y-Q, Hao Y-L, Han D-D, Zhang Y-L, You Z (2020) Laser fabrication of graphene-based flexible electronics. Adv Mater 32:1901981

33. Cui G, Bi Z, Zhang R, Liu J, Yu X, Li Z (2019) A comprehensive review on graphene-based anti-corrosive coatings. Chem Eng J 373:104-121

34. Wang Z-L, Xu D, Huang Y, Wu Z, Wang L-M, Zhang X-B (2012) Facile, mild and fast thermal-decomposition reduction of graphene oxide in air and its application in high-performance lithium batteries. Chem Commun 48:976-978

35. Berger C, Song Z, Li X, Wu X, Brown N, Naud C, Mayou D, Li T, Hass J, Marchenkov AN (2006) Electronic confinement and coherence in patterned epitaxial graphene. Science 312:1191-1196

36. Bae S, Kim H, Lee Y, Xu X, Park J-S, Zheng Y, Balakrishnan J, Lei T, Kim HR, Song YI (2010) Roll-to-roll production of 30 -inch graphene films for transparent electrodes. Nat Nanotechnol 5:574-578

37. He L, Pagneux Q, Larroulet I, Serrano AY, Pesquera A, Zurutuza A, Mandler D, Boukherroub R, Szunerits SJB (2017) Label-free femtomolar cancer biomarker detection in human serum using graphene-coated surface plasmon resonance chips. Biosens Bioelectron 89:606-611

38. Pei S, Cheng H-M (2012) The reduction of graphene oxide. Carbon 50:3210-3228

39. Choi W, Lahiri I, Seelaboyina R, Kang YS, Sciences M (2010) Synthesis of graphene and its applications: a review. J Crit Rev Solid State Mater Sci 35:52-71

40. Wan Z, Umer M, Lobino M, Thiel D, Nguyen N-T, Trinchi A, Shiddiky MJA, Gao Y, Li Q (2020) Laser induced self-N-doped porous graphene as an electrochemical biosensor for femtomolar miRNA detection. Carbon 163:385-394

41. Mamleyev ER, Heissler S, Nefedov A, Weidler PG, Nordin N, Kudryashov VV, Länge K, MacKinnon N, Sharma S (2019) Laserinduced hierarchical carbon patterns on polyimide substrates for flexible urea sensors. npj Flex Electron 3:1-11

42. Peng Z, Ye R, Mann JA, Zakhidov D, Li Y, Smalley PR, Lin J, Tour JM (2015) Flexible boron-doped laser-induced graphene microsupercapacitors. ACS Nano 9:5868-5875

43. Rao Y, Yuan M, Luo F, Wang Z, Li H, Yu J, Chen X (2021) Onestep laser fabrication of phosphorus-doped porous graphene electrodes for high-performance flexible microsupercapacitor. Carbon 180:56-66

44. Ge L, Hong Q, Li H, Liu C, Li F (2019) Direct-Laser-Writing of Metal Sulfide-Graphene Nanocomposite Photoelectrode toward Sensitive Photoelectrochemical Sensing. Adv Func Mater 29:1904000 
45. Dosi M, Lau I, Zhuang Y, Simakov DS, Fowler MW, Pope MA (2019) Ultrasensitive electrochemical methane sensors based on solid polymer electrolyte-infused laser-induced graphene. ACS Appl Mater Interfaces 11:6166-6173

46. Wei J, Sun Z, Luo W, Li Y, Elzatahry AA, Al-Enizi AM, Deng Y, Zhao D (2017) New insight into the synthesis of large-pore ordered mesoporous materials. J Am Chem Soc 139:1706-1713

47. Szunerits S, Boukherroub R (2018) Graphene-based biosensors. Interface Focus 8:20160132

48. Farré M, Barceló D (2020) Microfluidic devices: biosensors, Chemical Analysis of Food, Elsevier, pp 287-351

49. Ge L, Hong Q, Li H, Liu C, Li F (2019) Direct-laser-writing of metal sulfide-graphene nanocomposite photoelectrode toward sensitive photoelectrochemical sensing. Adv Funct Mater 29:1904000

50. Viswanathan S, Narayanan TN, Aran K, Fink KD, Paredes J, Ajayan PM, Filipek S, Miszta P, Tekin HC, Inci F (2015) Graphene-protein field effect biosensors: glucose sensing. Mater Today 18:513-522

51. Wan Z, Umer M, Lobino M, Thiel D, Nguyen N-T, Trinchi A, Shiddiky MJ, Gao Y, Li Q (2020) Laser induced self-N-doped porous graphene as an electrochemical biosensor for femtomolar miRNA detection. Carbon 163:385-394

52. Haque MH, Gopalan V, Yadav S, Islam MN, Eftekhari E, Li Q, Carrascosa LG, Nguyen N-T, Lam AK, Shiddiky MJ (2017) Detection of regional DNA methylation using DNA-graphene affinity interactions. Biosens Bioelectron 87:615-621

53. Xu G, Jarjes ZA, Wang H-W, Phillips AR, Kilmartin PA, TravasSejdic J (2018) Detection of neurotransmitters by three-dimensional laser-scribed graphene grass electrodes. ACS Appl Mater Interfaces 10:42136-42145

54. Kucherenko IS, Sanborn D, Chen B, Garland N, Serhan M, Forzani E, Gomes C, Claussen JC (2020) Ion-selective sensors based on laser-induced graphene for evaluating human hydration levels using urine samples. Adv Mater Technol 5:1901037

55. Umapathi S, Masud J, Coleman H, Nath M (2020) Electrochemical sensor based on $\mathrm{CuSe}$ for determination of dopamine. Microchim Acta 187:440

56. Senel M, Dervisevic E, Alhassen S, Dervisevic M, Alachkar A, Cadarso VJ, Voelcker NH (2020) Microfluidic electrochemical sensor for cerebrospinal fluid and blood dopamine detection in a mouse model of Parkinson's disease. Anal Chem 92:12347-12355

57. Hui X, Xuan X, Kim J, Park JY (2019) A highly flexible and selective dopamine sensor based on Pt-Au nanoparticle-modified laser-induced graphene. Electrochim Acta 328:135066

58. Rysz J, Gluba-Brzózka A, Franczyk B, Jabłonowski Z, Ciałkowska-Rysz A (2017) Novel biomarkers in the diagnosis of chronic kidney disease and the prediction of its outcome. Int J Mol Sci $18: 1702$

59. Jujo K, Minami Y, Haruki S, Matsue Y, Shimazaki K, Kadowaki H, Ishida I, Kambayashi K, Arashi H, Sekiguchi H (2017) Persistent high blood urea nitrogen level is associated with increased risk of cardiovascular events in patients with acute heart failure. ESC Heart Fail 4:545-553

60. Naz MY, Sulaiman SA (2016) Slow release coating remedy for nitrogen loss from conventional urea: a review. J Control Release 225:109-120

61. Mamleyev ER, Heissler S, Nefedov A, Weidler PG, Nordin N, Kudryashov VV, Länge K, MacKinnon N, Sharma S (2019) Laserinduced hierarchical carbon patterns on polyimide substrates for flexible urea sensors. npj Flex Electron 3:2

62. Dhawan G, Sumana G, Malhotra B (2009) Recent developments in urea biosensors. Biochem Eng J 44:42-52

63. Tehrani F, Bavarian B (2016) Facile and scalable disposable sensor based on laser engraved graphene for electrochemical detection of glucose. Sci Rep 6:27975
64. Lei Y, Alshareef AH, Zhao W, Inal S (2020) Laser-scribed graphene electrodes derived from lignin for biochemical sensing. ACS Appl Nano Mater 3:1166-1174

65. Huang W (2017) MicroRNAs: biomarkers, diagnostics, and therapeutics. In: Huang J, Borchert GM, Dou D, Huan J, Lan W, Tan $\mathrm{M}, \mathrm{Wu} \mathrm{B}$ (eds) Bioinformatics in MicroRNA research. Springer New York, New York, pp 57-67

66. Li X, Wu Y, Niu J, Jiang D, Xiao D, Zhou C (2019) One-step sensitive thrombin detection based on a nanofibrous sensing platform. J Mater Chem B 7:5161-5169

67. Fenzl C, Nayak P, Hirsch T, Wolfbeis OS, Alshareef HN, Baeumner AJ (2017) Laser-scribed graphene electrodes for aptamerbased biosensing. ACS Sensors 2:616-620

68. Schroeder HW Jr, Cavacini L (2010) Structure and function of immunoglobulins. J Allergy Clin Immunol 125:S41-S52

69. Barman SC, Zahed MA, Sharifuzzaman M, Ko SG, Yoon H, Nah JS, Xuan X, Park JY (2020) A polyallylamine anchored aminerich laser-ablated graphene platform for facile and highly selective electrochemical IgG biomarker detection. Adv Func Mater 30:1907297

70. Beduk T, Beduk D, de Oliveira Filho JI, Zihnioglu F, Cicek C, Sertoz R, Arda B, Goksel T, Turhan K, Salama KN, Timur S (2021) Rapid point-of-care COVID-19 diagnosis with a goldnanoarchitecture-assisted laser-scribed graphene biosensor. Anal Chem 93:8585-8594

71. Nguyen P, Berry V (2012) Graphene interfaced with biological cells: opportunities and challenges. J Phys Chem Lett 3:1024-1029

72. Le JD, Pinto Y, Seeman NC, Musier-Forsyth K, Taton TA, Kiehl RA (2004) DNA-templated self-assembly of metallic nanocomponent arrays on a surface. Nano Lett 4:2343-2347

73. Puetz P, Behrent A, Baeumner AJ, Wegener J (2020) Laserscribed graphene (LSG) as new electrode material for impedance-based cellular assays. Sensors Actuators B Chem $321: 128443$

74. Zhang Y, Zhu H, Sun P, Sun C-K, Huang H, Guan S, Liu H, Zhang $\mathrm{H}$, Zhang C, Qin K-R (2019) Laser-induced graphene-based nonenzymatic sensor for detection of hydrogen peroxide. Electroanalysis 31:1334-1341

75. Xu G, Jarjes ZA, Desprez V, Kilmartin PA, Travas-Sejdic J (2018) Sensitive, selective, disposable electrochemical dopamine sensor based on PEDOT-modified laser scribed graphene. Biosens Bioelectron 107:184-191

76. Zhu J, Liu S, Hu Z, Zhang X, Yi N, Tang K, Dexheimer MG, Lian X, Wang Q, Yang J (2021) Laser-induced graphene non-enzymatic glucose sensors for on body measurements. Biosens Bioelectron 193:113606

77. Zahed MA, Barman SC, Das PS, Sharifuzzaman M, Yoon HS, Yoon SH, Park JY (2020) Bioelectronics, Highly flexible and conductive poly (3, 4-ethylene dioxythiophene)-poly (styrene sulfonate) anchored 3-dimensional porous graphene network-based electrochemical biosensor for glucose and $\mathrm{pH}$ detection in human perspiration. Biosens Bioelectron 160:112220

78. Torrente-Rodríguez RM, Tu J, Yang Y, Min J, Wang M, Song Y, Yu Y, Xu C, Ye C, IsHak WW (2020) Investigation of cortisol dynamics in human sweat using a graphene-based wireless mHealth system. Matter 2:921-937

79. Vanegas DC, Patiño L, Mendez C, de Oliveira DA, Torres AM, Gomes CL, McLamore ES (2018) Laser scribed graphene biosensor for detection of biogenic amines in food samples using locally sourced materials. Biosensors (Basel) 8:42

80. Soares RRA, Hjort RG, Pola CC, Parate K, Reis EL, Soares NFF, McLamore ES, Claussen JC, Gomes CL (2020) Laser-induced graphene electrochemical immunosensors for rapid and label-free monitoring of Salmonella enterica in chicken broth. ACS Sensors 5:1900-1911 
81. Heo JI, Shim DS, Teixidor GT, Oh S, Madou MJ, Shin H (2011) Carbon interdigitated array nanoelectrodes for electrochemical applications. J Electrochem Soc 158:J76

82. Lan L, Le X, Dong H, Xie J, Ying Y, Ping J (2020) One-step and large-scale fabrication of flexible and wearable humidity sensor based on laser-induced graphene for real-time tracking of plant transpiration at bio-interface. Biosens Bioelectron 165:112360

83. Marengo M, Marinaro G, Kosel J (2017) Flexible temperature and flow sensor from laser-induced graphene, 2017 IEEE SENSORS, IEEE, pp 1-3

84. Lee H, Song C, Hong YS, Kim MS, Cho HR, Kang T, Shin K, Choi SH, Hyeon T, Kim D-H (2017) Wearable/disposable sweatbased glucose monitoring device with multistage transdermal drug delivery module. Sci Adv 3:e1601314

85. Liu Y-Q, Chen Z-D, Mao J-W, Han D-D, Sun X (2019) Laser fabrication of graphene-based electronic skin. Front Chem 7:461

86. Tao L-Q, Tian H, Liu Y, Ju Z-Y, Pang Y, Chen Y-Q, Wang D-Y, Tian X-G, Yan J-C, Deng N-Q (2017) An intelligent artificial throat with sound-sensing ability based on laser induced graphene. Nat Commun 8:1-8

87. Rahimi R, Ochoa M, Yu W, Ziaie B (2015) Highly stretchable and sensitive unidirectional strain sensor via laser carbonization. ACS Appl Mater Interfaces 7:4463-4470
88. Luo S, Hoang PT, Liu T (2016) Direct laser writing for creating porous graphitic structures and their use for flexible and highly sensitive sensor and sensor arrays. Carbon 96:522-531

89. Xuan X, Kim JY, Hui X, Das PS, Yoon HS, Park J-Y (2018) A highly stretchable and conductive $3 \mathrm{D}$ porous graphene metal nanocomposite based electrochemical-physiological hybrid biosensor. Biosens Bioelectrons 120:160-167

90. Zhong H, Zhu Z, Lin J, Cheung CF, Lu VL, Yan F, Chan C-Y, Li G (2020) Reusable and recyclable graphene masks with outstanding superhydrophobic and photothermal performances. ACS Nano 14:6213-6221

91. Huang L, Xu S, Wang Z, Xue K, Su J, Song Y, Chen S, Zhu C, Tang BZ, Ye R (2020) Self-reporting and photothermally enhanced rapid bacterial killing on a laser-induced graphene mask. ACS Nano 14:12045-12053

92. Huang Y, Tao L-Q, Yu J, Wang Z, Zhu C, Chen X (2020) Integrated sensing and warning multifunctional devices based on the combined mechanical and thermal effect of porous graphene. ACS Appl Mater Interfaces 12:53049-53057

Publisher's note Springer Nature remains neutral with regard to jurisdictional claims in published maps and institutional affiliations. 